\title{
The colonial ascidian Diplosoma
} listerianum enhances the occurrence of the hydrozoan Obelia sp. during early phases of succession

\author{
I. Krüger ${ }^{1,5,6}$, M. Lenz $2^{*}$ (1) and M. Thiel $\left.\right|^{3,4,5,6}$
}

\begin{abstract}
Recruitment patterns of sessile species often do not reflect the composition of the local propagule pool. This is, among other processes, attributed to the stimulation or inhibition of settlement by resident species. In an experimental study, we evaluated the effects of different densities of the ascidian Diplosoma listerianum on the settlement of the hydrozoan Obelia sp. For this, we monitored the cover of the dominant fouler Obelia sp. on vertically orientated PVC tiles, which were either bare or pre-seeded with two different densities (sparse or dense) of Diplosoma colonies, over the course of 8 weeks. The settlement tiles were deployed at two study sites in La Herradura Bay, Chile. The presence of $D$. listerianum enhanced the settlement or the growth or both of the colonial hydrozoan, but this effect disappeared within 4-8 weeks. Furthermore, we tested whether the initial enhancement of Obelia sp. by Diplosoma colonies goes back to the fact that larvae, which reject the ascidian tunic as a settlement substratum after a first contact, colonize nearby surfaces because of their limited mobility. However, we found no support for this assumption. We rather suggest that $D$. listerianum facilitated colonization indirectly by the accumulation of organic material in its vicinity and/or by its pumping activity. Initial resident-mediated enhancement of the hydrozoan was overridden by processes such as competition between later colonizers within the course of weeks and we could not detect any lasting effects of $D$. listerianum on the structure of the developing communities.
\end{abstract}

Keywords: Hard-bottom communities, Settlement, Facilitation, Diplosoma listerianum, Obelia sp.

\section{Introduction}

To understand the processes controlling substratum colonization by marine sessile invertebrates and macroalgae, it is important to distinguish between settlement and recruitment. While settlement exclusively refers to the moment of adhesion, recruitment also includes the successful survival and growth of a settler over longer time scales [e.g. 1, 2]. Both, settlement and post-settlement survival are strongly influenced by the presence and abundance of resident species [3, 4]. Several macroinvertebrates suppress recruitment by preying on larvae of

\footnotetext{
*Correspondence: mlenz@geomar.de

${ }^{2}$ Marine Ecology Department, GEOMAR Helmholtz Centre of Ocean

Research Kiel, Duesternbrooker Weg 20, 24105 Kiel, Germany

Full list of author information is available at the end of the article
}

other settlers [5], while epizoans as well as macroalgae can preempt settlement substrata, facilitate or inhibit larval settlement [5-7], and reduce the availability of resources such as light, food, and gases [8].

Because of their tolerance towards abiotic stresses and disturbances, colonial ascidians are ubiquitous in marine fouling communities worldwide [9]. Furthermore, they are notorious for being highly successful invaders that can dominate available substrata to large extents. An area of $230 \mathrm{~km}^{2}$ at Georges Bank, USA, was (in a depth range of 45-60 m) observed to be covered by the invasive Didemnum sp. by up to $90 \%$ [10]. In many benthic habitats worldwide settlers can encounter colonial ascidians during the colonization process, and a few experimental and observational studies so far confirmed that these can 
influence the settlement and recruitment of other organisms or the succession of communities [11-14].

Colonial ascidians of the genus Diplosoma (MacDonald 1859) are typical macrofoulers on man-made substrata in temperate regions and they are among the most widespread cosmopolitan marine species [15]. Especially during the early succession of fouling communities on previously bare substrata, when open space is plenty, the fast-growing Diplosoma colonies can reach high abundances and overgrow other recruits [11]. Like many colonial ascidians, Diplosoma can keep its surface clear of fouling [16] and thereby efficiently preempt settlement substratum. Their defensive mechanisms have not been identified in all details, but several chemical and mechanical traits have been suggested [15]. A further possible explanation for the resistance of Diplosoma to fouling may be the acidity of its tunic [17-20]. Although we have some knowledge about how Diplosoma wards off foulers and consumers, it is still unclear if and in which way it affects settlement in its direct vicinity. Previous experiments designed to answer this question showed contrasting results. On the one hand, Diplosoma was observed to reduce the settlement of the polychaete Spirorbis sp. (Daudin 1800) and of other colonial ascidians, e.g. Botryllus schlosseri (Pallas 1766) and Botrylloides sp. (MilneEdwards 1841), on adjacent surfaces [21], while, on the other hand, the settlement of larvae was found to be enhanced in the direct vicinity of Diplosoma [11]. The latter was attributed to a "switching behaviour" of incoming larvae, which, due to being limited in their mobility, settle on adjacent surfaces after having first contacted and rejected the tunic of the ascidians [11]. Also Obelia spp. was found to be negatively affected by ascidians [22], because the hydrozoan was absent on ascidian-dominated settlement plates, possibly because it was impaired by other primary settlers, including soft corals [23].

We studied if and how Diplosoma listerianum influences the expansion (settlement and colonial growth) of another common and abundant fouler, the hydrozoan Obelia sp. (Péron and Lesueur 1810) and whether effects are consistent on small temporal and spatial scales. The following questions were addressed: (1) Does the presence of $D$. listerianum, apart from the pre-emption of space, influence the cover by Obelia sp.? (2) Is the effect a function of ascidian density?

\section{Materials and methods}

\section{Study sites and preparation of settlement tiles}

Two study sites within a distance of $700 \mathrm{~m}$ in the La Herradura Bay in northern-central Chile were chosen for this experiment. One site ("site $\mathrm{A}$ " in the following), near the Universidad Católica del Norte, is close to the west-facing mouth of the bay and therefore exposed to the prevailing southwesterly winds as well as wind-induced waves and currents. The other site ("site B" in the following) is in the interior part of the bay next to the Compañía Minera del Pacífico. It is sheltered due to being located behind the iron loading pier of the company, which reduces wave action substantially [24]. Natural hard-bottom substrata in both areas are mostly dominated by crustose algae, while, because of the impact of benthic predators, only few animal colonizers can successfully establish $[25,26]$. Diplosoma listerianum is one of the most dominant settlers in this environment. In a study in the same system it was found that the genus colonized up to $40 \%$ of the surface of bare substrata (plastic, pumice and styrofoam), which had been exposed in the bay for $\sim 14$ weeks [27].

In February 2006, colonies of Diplosoma were carefully cut into small sub-colonies (approximately $2 \mathrm{~cm} \times 2 \mathrm{~cm}$ ) and scraped off their substratum with a scalpel. They were then transplanted onto 36 PVC tiles, $15 \mathrm{~cm} \times 15 \mathrm{~cm}$, roughened with sandpaper (grain size 60). We distributed the colonies evenly (similar distances between adjacent colonies) across the tiles by placing them on the tiles without any further support to facilitate adhesion. For the following 4 days, we kept the tiles in a horizontal position within a flow-through seawater system to allow re-attachment of the colonies. On day five the water flow was gradually increased and colonies showing signs of detachment from the tiles were removed. This procedure was repeated every second day until $80 \%$ of the remaining colonies had attached firmly after 6 days. The transplantation process had no visible negative effects on the animals and once they had attached, survival rates were high. After two more weeks of incubation in the laboratory, tiles were fixed to ring-shaped constructions with a diameter of $\sim 90 \mathrm{~cm}$ made of plastic coated wire. They were positioned vertically on the interior surface of the ring and the side that had the ascidian colonies faced the center of the ring. Rings were then transported to the study sites. There, their lower ends were attached to a bottom weight, while their upper ends were fixed to a buoy to position them in a water depth of $\sim 50 \mathrm{~cm}$. This was done prior to the main experiment to test whether the re-attached ascidian colonies survive and grow under field conditions. The tiles were brought back to the laboratory 2 weeks later to generate various densities of Diplosoma by removing colonies to different degrees.

\section{Experimental design and treatments}

To have three levels of ascidian cover, the 36 tiles with Diplosoma were randomly allocated into three groups of 12. In one group, all tiles were completely cleaned (referred to as 'control tiles' in the following), while a second set of 12 tiles was carefully cleared of all ongrowth, but of 5 homogenously distributed $1 \mathrm{~cm}^{2}$ patches of 
Diplosoma. The remaining 12 replicates were prepared to have 15 evenly distributed $1 \mathrm{~cm}^{2}$ patches of ascidian colonies. A final inspection with a stereomicroscope re-assured that tiles were free of organisms other than Diplosoma. Thereafter, we allocated three randomly chosen replicates of each treatment level to one ring-construction; two rings were then deployed at site A, while the remaining two were suspended at site B. Each treatment combination had $\mathrm{n}=6$ replicates. For the following two months (March and April 2006), the tiles were exposed to natural fouling and were sampled after 2, 4, 6 and 8 weeks (March 7th-April 18th 2006).

\section{Sampling}

At each sampling event all tiles were detached from the rings and transferred to the laboratory, where they were kept submerged in a tank with a seawater flow-through system. Percent cover of all macrofoulers $>2 \mathrm{~mm}$ in diameter or height was estimated by the naked eye to the nearest $5 \%$ without using a grid or any other visual aid [28], while we excluded a $10 \mathrm{~mm}$ wide margin along all sides of the tiles with a plastic frame. This was done to avoid the sampling of edge effects. We recorded the amount of free space, i.e. tile surface that was not covered by any macroorganisms, as well as all cases of multistrata growth. The latter allowed coverage per tile to exceed $100 \%$. We re-attached all tiles to the rings within $3 \mathrm{~h}$ and deployed them again at their site of origin. Since we never observed recruits growing on the Diplosoma colonies but only on bare tile surface, we viewed the tunicates as space that was not available for colonization. We therefore related the observed cover to the tile surface not occupied by Diplosoma using the following formula:

\section{Percent cover of a given species on}

the available tile surface area

$$
=(((\mathrm{A} * \mathrm{C}) / 100) /(\mathrm{A}-\mathrm{D})) * 100
$$

with $\mathrm{A}=$ total tile surface area excluding a $1 \mathrm{~cm}$ margin $\left(=169 \mathrm{~cm}^{2}\right), \mathrm{C}=$ species cover (in \%), $\mathrm{D}=$ tile surface area covered by Diplosoma (in $\left.\mathrm{cm}^{2}\right),\left(\mathrm{A}^{*} \mathrm{C}\right) / 100=$ area (in $\mathrm{cm}^{2}$ ) covered by a given species other than Diplosoma, $A-D=$ effectively available tile surface area (surface free of Diplosoma).

We also assessed the richness, i.e. number of species, of the establishing fouling communities. On tiles that had initial Diplosoma cover, the ascidian was only counted in case it recruited again from the water column during the experiment.

\section{Statistical analysis}

We tested whether initial Diplosoma density had an effect on Obelia sp. cover with repeated measures ANOVA that was calculated as a mixed-effect model.
We included 'Density' with three levels $(0,5,15$ colonies per tile), 'Site' with two levels (site A, site B) and 'Week' with four levels (week 2, week 4, week 6, week 8) as fixed factors in this design, while the repeatedly measured replicates were treated as the random factor. This analysis was conducted with (a) the total available tile surface area, and (b) the effectively available tile surface area. This was done to determine whether a switching behaviour, i.e. larvae rejecting the surface of Diplosoma on the adjacent tile surface [11], could be responsible for increased recruitment in the direct vicinity of the Diplosoma colonies. For the first analysis, we related Obelia sp. cover to the total tile surface area, which was not corrected for the presence of Diplosoma colonies. If larvae were not attracted by the presence of the ascidian and only switched from colonies to nearby PVC surfaces, this analysis should not reveal any differences in fouler cover between Diplosoma density levels. However, if there was a Diplosoma-mediated enhancement in fouler recruitment, for instance because larvae were attracted or because their attachment and survival was facilitated by the ascidian, the abundances of Obelia sp. recruits should change with tunicate cover. Furthermore, we tested for effects of Diplosoma density on the expansion (settlement and colonial growth) of the hydrozoan on the effectively available tile surface. We removed one data point from this data set, because it had a strong influence on the model.

We used residual plots to check for normality of errors and to test for homogeneity of variances. Obelia sp. cover data were square-root transformed prior to the analysis. For the last sampling day, we correlated the amount of cover by Obelia sp. with the cover of the six most abundant fouling organisms using Spearman's rank correlations. This was done to identify whether any of the present species correlated positively or negatively with Obelia sp. cover. We used the data from all tiles regardless of initial Diplosoma cover and site.

\section{Results}

During the 8 week-long experimental period, we observed a total of 14 sessile taxa. Three hydrozoans: Obelia sp., Tubularia sp. (Linnaeus 1758), and one unidentified species; three bryozoans: Bugula neritina (Linnaeus 1758), B. flabellata (Thompson in Gray 1848) and one unidentified species; three ascidians: Ciona intestinalis (Linnaeus 1767), Pyura chilensis (Molina 1782) and Diplosoma listerianum; two brown algae: Scytosiphon sp. (Agardh 1820) and Ectocarpus sp. (Lyngbye 1819). Furthermore, we found the red alga Polysiphonia sp. (Greville 1823), green algae belonging to the Ulvales (Blackman and Tansley 1902), and benthic diatoms. The list also includes newly settled colonies of $D$. listerianum, 
while the two most abundant taxa were the hydrozoan Obelia sp. and the bryozoan Bugula neritina.

The previously established Diplosoma colonies grew fast during the first two weeks and covered between 10 and 30\% (initially 5 colonies) and 50-60\% (initially 15 colonies) of the tiles' surface at the end of this period, respectively. After this, however, Diplosoma cover decreased on all replicates except on the sparsely covered tiles at site B (data not shown).

Two weeks after the onset of natural colonization, we found a pronounced influence of initial Diplosoma cover on the presence of the hydrozoan on total tile surface area at both study sites (Fig. 1, Table 1). It was higher in the presence of a dense Diplosoma cover, i.e. 15 colonies, than (a) on control tiles (at site B), and (b) on control tiles and sparsely covered tiles, i.e. with 5 Diplosoma colonies (at site A) (Fig. 1).

The effect of Diplosoma cover on Obelia sp., however, became indiscernible within 4 weeks at site $\mathrm{A}$ and within 6 weeks at site B. This is reflected in a significant interaction between Diplosoma density and the time that elapsed since the start of the experiment (Table 1).

When considering only the effectively available tile surface area the picture is very similar. For these data,
Table 1 Influence of the initial density of Diplosoma listerianum colonies (D), site (S) of exposure and weeks since start of the experiment (W) on the recruitment of the hydrozoan Obelia sp. on the total tile surface area during 8 weeks of fouling community succession

\begin{tabular}{llllr}
\hline Source of variation & DF $_{\text {numerator }}$ & DF $_{\text {denominator }}$ & \multicolumn{1}{l}{ F } & \multicolumn{1}{c}{ P } \\
\hline$D$ & 2 & 30 & 4.55 & $\leq 0.05$ \\
$S$ & 1 & 30 & 1.21 & 0.23 \\
$W$ & 3 & 90 & 2.99 & $\leq 0.05$ \\
$D \times S$ & 2 & 30 & 1.49 & 0.24 \\
$D \times W$ & 6 & 90 & 2.64 & $\leq 0.05$ \\
$S \times W$ & 3 & 90 & 5.42 & $\leq 0.01$ \\
$D \times S \times W$ & 6 & 90 & 1.21 & 0.31
\end{tabular}

Results from repeated-measures ANOVA

again, the main effect of initial Diplosoma cover and the interaction between cover and time since start of the experiment were significant (Table 2). At site B, the effect even persisted until the 8th week of the experiment (Fig. 2, Table 2), while it disappeared within 6 weeks at site A.

Similar to the effect on Obelia sp. cover, the initial presence of Diplosoma had a positive effect on fouler

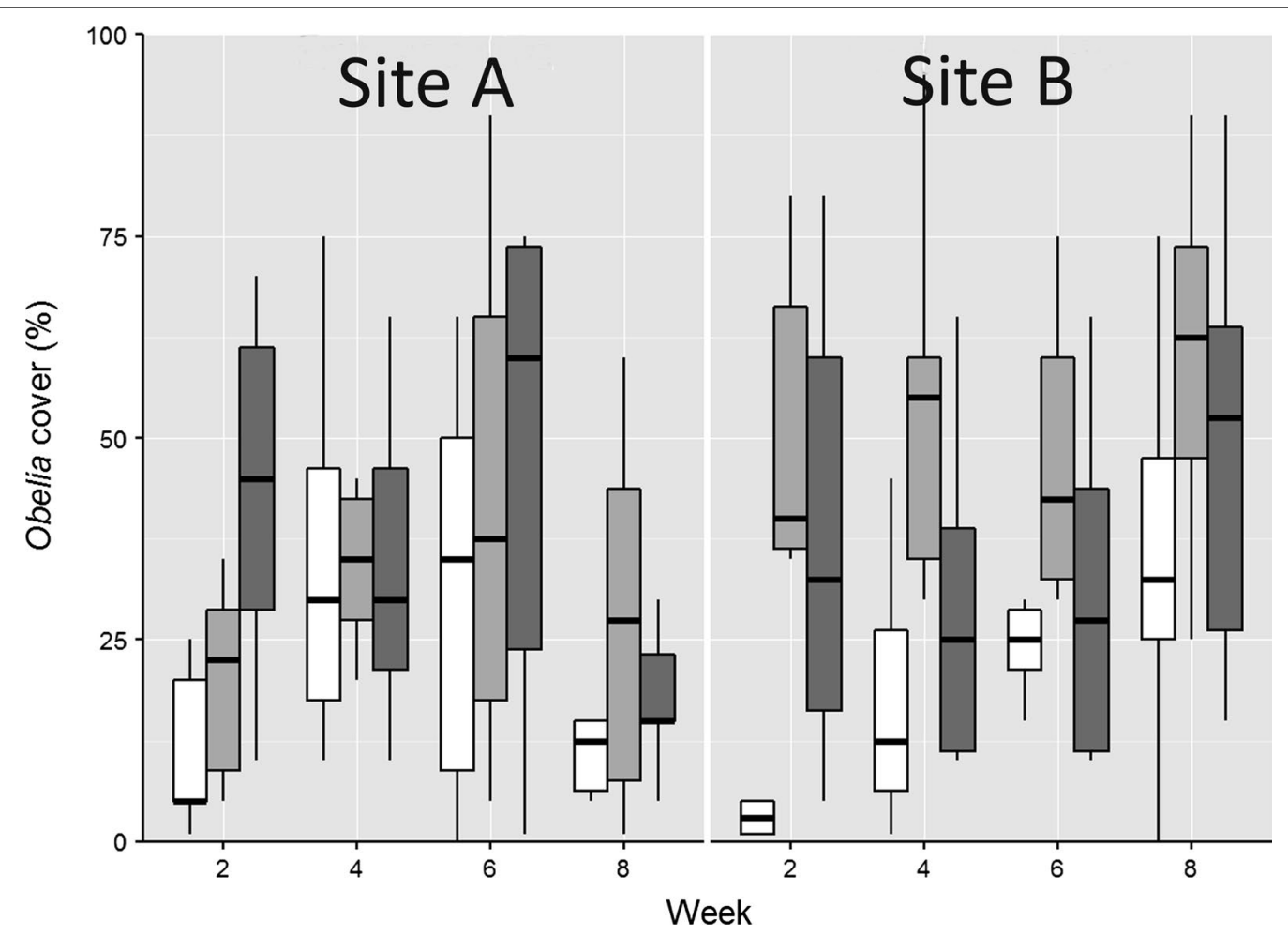

Fig. 1 Influence of Diplosoma listerianum colony density on recruitment by Obelia sp. Settlement tiles were deployed at two sites in La Herradura Bay, Chile, over the course of 8 weeks. Tiles had different initial densities of Diplosoma listerianum colonies (white $=0$, medium grey $=5$ and dark grey $=15$ ). Percent cover by Obelia sp. relates to the total tile surface area. Boxes and whiskers show medians, interquartiles and non-outlier ranges 
Table 2 Influence of the initial density of Diplosoma listerianum colonies (D), site (S) of exposure and weeks since start of the experiment (W) on the recruitment of the hydrozoan Obelia sp. on the effectively available tile surface area (total area-initial Diplosoma cover) during 8 weeks of fouling community succession

\begin{tabular}{lllrc}
\hline Source of variation & $\mathbf{D F}_{\text {numerator }}$ & $\mathbf{D F}_{\text {denominator }}$ & $\mathbf{p}$ \\
\hline $\mathrm{D}$ & 2 & 30 & 15.11 & $\leq 0.001$ \\
$\mathrm{~S}$ & 1 & 30 & 4.26 & $\leq 0.05$ \\
$\mathrm{~W}$ & 3 & 89 & 1.12 & 0.34 \\
$\mathrm{D} \times \mathrm{S}$ & 2 & 30 & 2.94 & 0.07 \\
$\mathrm{D} \times \mathrm{W}$ & 6 & 89 & 4.80 & $\leq 0.001$ \\
$\mathrm{~S} \times \mathrm{W}$ & 3 & 89 & 1.78 & 0.16 \\
$\mathrm{D} \times \mathrm{S} \times \mathrm{W}$ & 6 & 89 & 1.41 & 0.22 \\
\hline
\end{tabular}

Results from repeated measures ANOVA

recruitment in general. Total cover was enhanced by Diplosoma at both sites, but this effect was again restricted to the first 2 weeks of colonization and disappeared thereafter (Fig. 3, Table 3). At site A total cover was only enhanced in the presence of 15 Diplosoma colonies, while at site $\mathrm{B}$ already 5 colonies had this effect.
There was an influence of initial Diplosoma cover on communities' species richness, but it varied strongly between sites and in time. This is reflected in a significant 3-way interaction, while the main effect of density is insignificant. However, the main effects of site of exposure and weeks since start of experiment are significant (Fig. 4, Table 4).

All tiles, regardless of initial Diplosoma cover and site of exposure, showed a minimum median cover of $81 \%$ after 8 weeks of ongoing colonization. Furthermore, we observed that the formation of biofilms, i.e. bacteria and benthic diatoms, was increased near Diplosoma colonies (Ina Krüger pers. obs.). At the last sampling day, coverage by two colonizers correlated negatively with Obelia sp. cover. This was the case for the brown alga Ectocarpus sp. (Rho $=-0.34, \mathrm{p} \leq 0.05)$ and for green algae of the Ulvales (Rho $=-0.34, \mathrm{p} \leq 0.05$ ), while there was no significant correlation between Obelia sp. and (a) D. listerianum, (b) the bryozoan $B$. neritina, (c) the red alga Polysiphonia sp., as well as (d) the hydrozoan Tubularia sp. These six species together constituted $70 \%$ of the cover on all tiles.

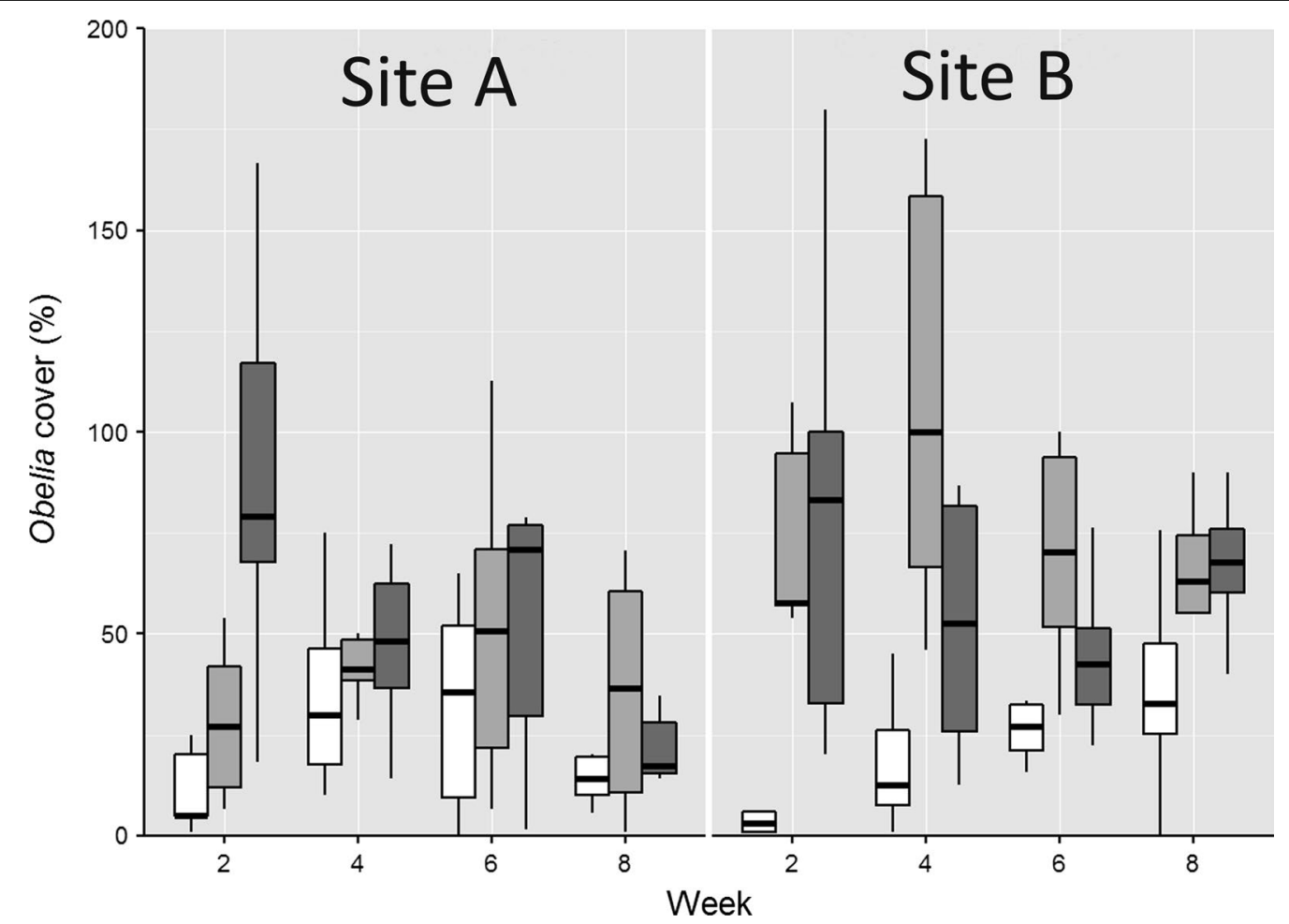

Fig. 2 Influence of Diplosoma listerianum colony density on recruitment by Obelia sp. Settlement tiles were deployed at two sites in La Herradura Bay, Chile, over the course of 8 weeks. Tiles had different initial densities of Diplosoma listerianum colonies (white $=0$, medium grey $=5$ and dark grey $=15$ ). Percent cover by Obelia sp. relates to the effectively available tile surface area. Boxes and whiskers show medians, interquartiles and nonoutlier ranges 


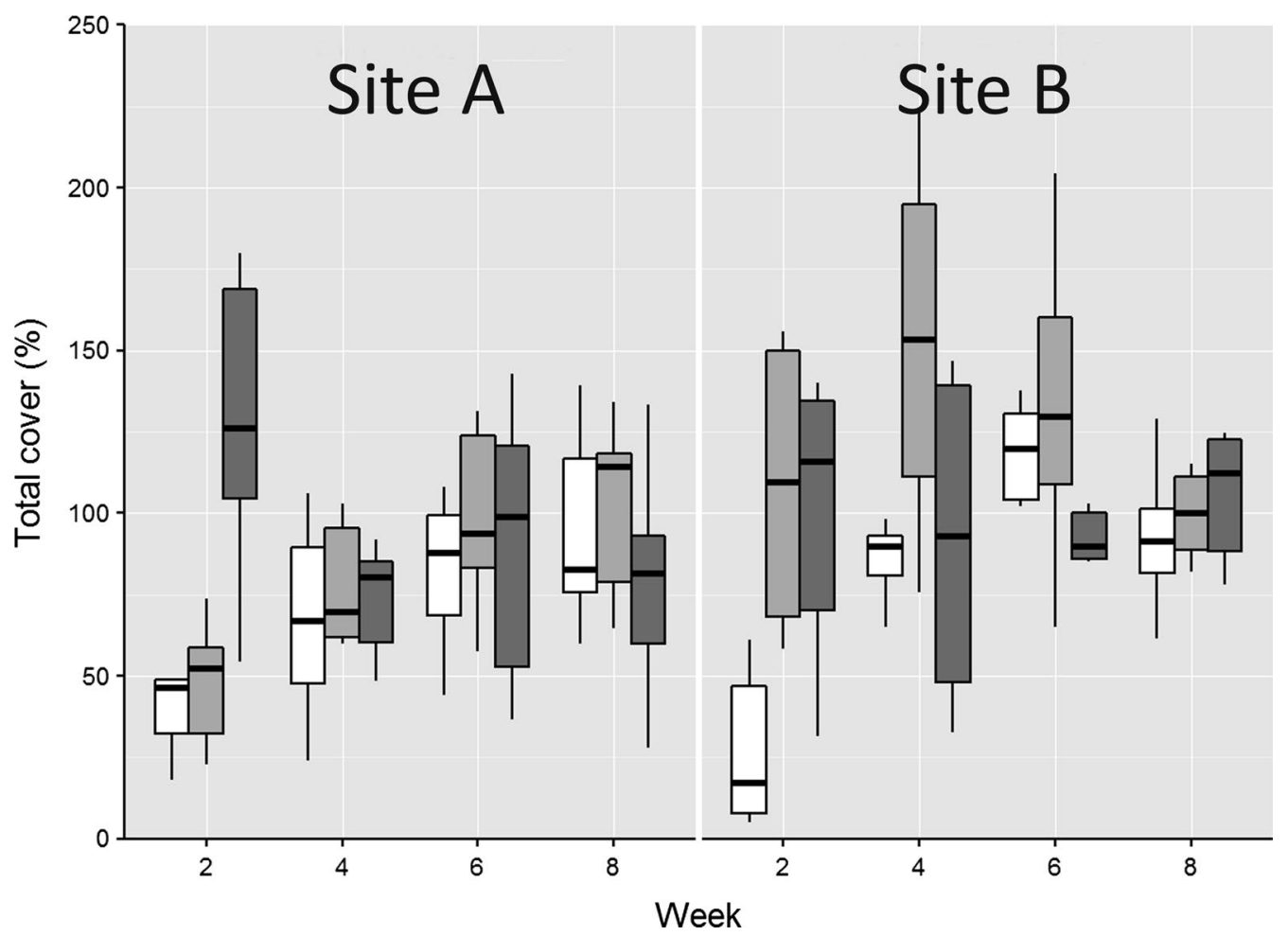

Fig. 3 Influence of Diplosoma listerianum colony density on total cover by fouling organisms. Settlement tiles were deployed at two sites in La Herradura Bay, Chile, over the course of 8 weeks. Tiles had different initial densities of Diplosoma listerianum colonies (white $=0$, medium grey $=5$ and dark grey $=15$ ). Total cover relates to the effectively available tile surface area. Boxes and whiskers show medians, interquartiles and non-outlier ranges

Table 3 Influence of the initial density of Diplosoma listerianum colonies (D), site (S) of exposure and weeks since start of the experiment (W) on total cover by fouling organisms on the effectively available tile surface area (total tile area-initial Diplosoma cover) during 8 weeks of succession

\begin{tabular}{llllr}
\hline Source of variation & $\mathbf{D F}_{\text {numerator }}$ & $\mathbf{D F}_{\text {denominator }}$ & $\mathbf{F}$ & $\mathbf{p}$ \\
\hline D & 2 & 30 & 5.51 & $\leq 0.01$ \\
S & 1 & 30 & 5.20 & $\leq 0.05$ \\
$W$ & 3 & 90 & 2.72 & $\leq 0.05$ \\
$D \times S$ & 2 & 30 & 1.02 & 0.37 \\
$D \times W$ & 6 & 90 & 3.15 & $\leq 0.01$ \\
$S \times W$ & 3 & 90 & 1.42 & 0.24 \\
$D \times S \times W$ & 6 & 90 & 1.27 & 0.28 \\
\hline
\end{tabular}

Results from repeated measures ANOVA

\section{Discussion}

The initial presence of Diplosoma listerianum on otherwise bare tiles had a positive effect on the cover of the hydrozoan Obelia sp. within the first weeks of succession. When interpreting this effect, it is important to note that the abundance of the hydrozoan is determined by settlement rates of larvae and/or vegetative fragments as well as by post-settlement colonial growth or by a combination of these processes. Since the hydrozoan grew fast, we were not able to identify unambiguously which mechanism drove the pattern we observed. However, the positive influence was consistent between the two study sites when Diplosoma was present in high abundances (15 colonies per $169 \mathrm{~cm}^{2}$ ), while low Diplosoma cover (5 colonies per $169 \mathrm{~cm}^{2}$ ) affected hydrozoan cover only at one of the sites (site B). Furthermore, the effect of initial Diplosoma cover on Obelia sp. lasted longer at site B than at site A. In contrast to previous studies that reported negative effects of colonial ascidians on other colonizers $[11,14]$, we found that the presence of this compound ascidian had a positive or no influence on the presence of the highly abundant fouler Obelia sp. as well as on the total cover by fouling organisms that established on the settlement tiles in this study. Interestingly, there was no clear influence of initial Diplosoma cover on the number of species present in the fouling communities.

In a previous study several fouling species, such as bryozoans, polychaetes and cirripedes, showed aggregated settlement on open surfaces adjacent to colonies of Diplosoma [11]. This was attributed to limited larval mobility after first substratum contact, which led to the 


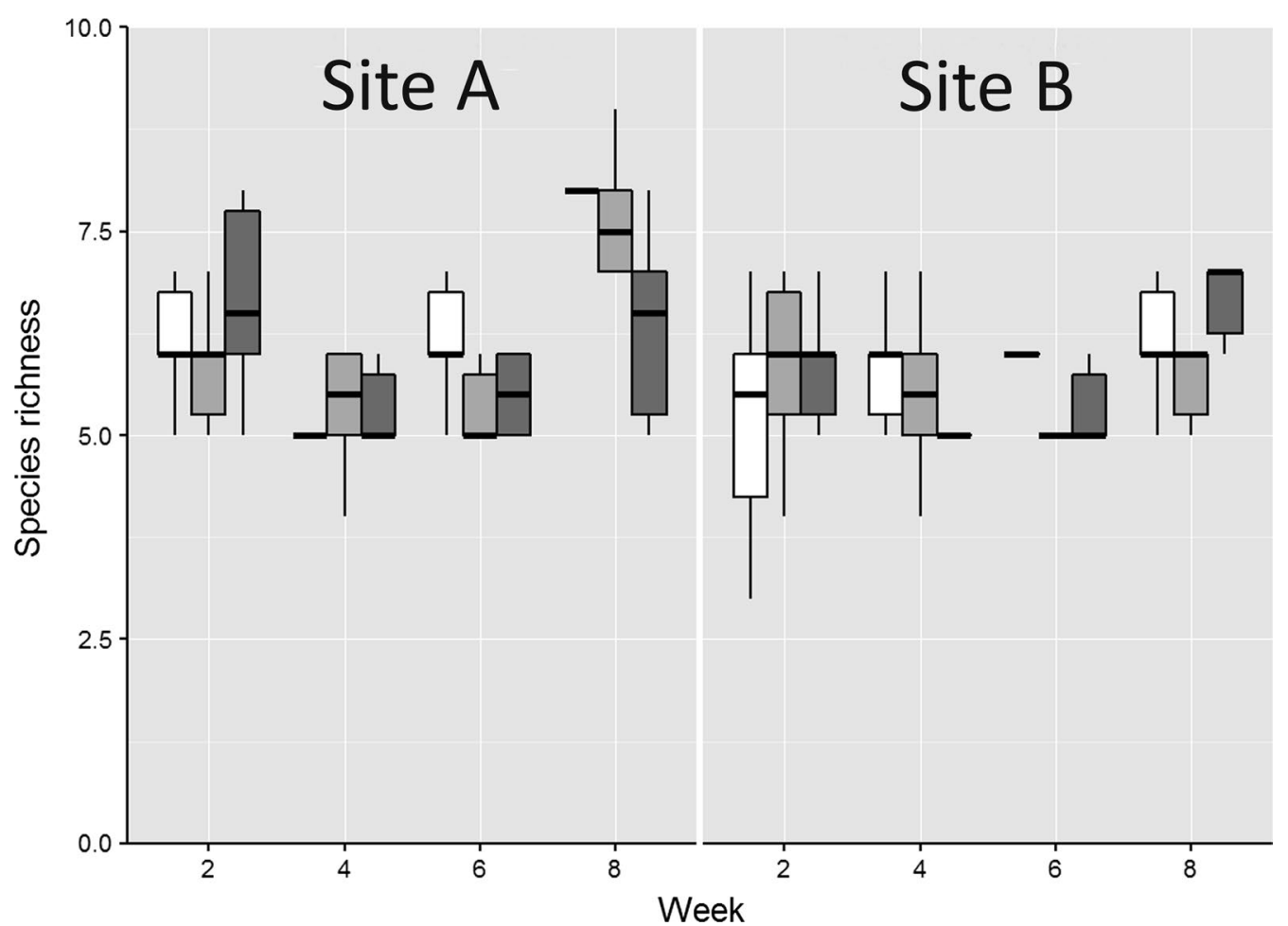

Fig. 4 Influence of Diplosoma listerianum colony density on species richness of the establishing fouling communities. Settlement tiles were deployed at two sites in La Herradura Bay, Chile, over the course of 8 weeks. Tiles had different initial densities of Diplosoma listerianum colonies ( white $=0$, medium grey $=5$ and dark grey $=15$ ). On tiles that had initial Diplosoma listerianum cover, the species was only counted in case it recruited again during the experiment. Boxes and whiskers show medians, interquartiles and non-outlier ranges

Table 4 Influence of the initial density of Diplosoma listerianum colonies (D), site (S) of exposure and weeks since start of the experiment $(\mathrm{W})$ on species richness of the establishing fouling communities during 8 weeks of succession

\begin{tabular}{lllrr}
\hline Source of variation & $\mathbf{D F}_{\text {numerator }}$ & $\mathbf{D F}_{\text {denominator }}$ & \multicolumn{1}{l}{$\mathbf{F}$} & $\mathbf{p}$ \\
\hline D & 2 & 30 & 1.29 & 0.29 \\
S & 1 & 30 & 6.76 & $\leq 0.05$ \\
W & 3 & 90 & 16.17 & $\leq 0.001$ \\
$D \times S$ & 2 & 30 & 0.11 & 0.90 \\
$D \times W$ & 6 & 90 & 1.77 & 0.11 \\
$S \times W$ & 3 & 90 & 4.74 & $\leq 0.01$ \\
$D \times S \times W$ & 6 & 90 & 3.07 & $\leq 0.01$ \\
\hline
\end{tabular}

Results from repeated measures ANOVA

immediate colonization of nearby areas after the larvae rejected the ascidian tunica as a settlement substratum. This was called 'switching behaviour' and it was concluded that the positive effect of tunicate presence on other colonizers was only because of the pre-emption of space and that no settlement cues attracted the larvae. This assumption was supported by the observation that the total number of colonizers per settlement tiles was lower in the presence of the tunicate than on their ascidian-free control tiles [11].

In contrast to these findings, in our experiment the settlement near tunicate colonies as well as the total settlement per tile was positively related to Diplosoma densities. As a consequence, larval switching to adjacent areas after rejecting the ascidians as a settlement substratum cannot be the explanation for increased settlement rates near Diplosoma colonies. Furthermore, in our study the presence of Diplosoma colonies had no influence on the number of species that established on the settlement tiles.

The fact that ascidians can consume invertebrate larvae $[11,15,29]$, and that their tunics may have antifouling properties [30] makes a direct facilitative effect or even the attraction of colonizers by Diplosoma unlikely. We therefore suggest other mechanisms that could have enhanced the settlement and/or the post-settlement growth of the hydroid. The first explanatory model is based on the observation that during the experiment, biogenic material accumulated near Diplosoma colonies, which led to the formation of a biofilm that was presumably richer than on other parts of the tiles. Since the material presumably stemmed from the tunicates, i.e. 
faeces or mucus, it is possible that these products during their decay enhanced the growth of bacteria and diatoms in the direct vicinity of the ascidians. Such biofilms are ubiquitous in the marine environment [31-33], and play an important role in the colonization of surfaces. They consist of bacteria, diatoms, and extracellular material/ exopolymers and may have inhibitive [34-36] as well as facilitative effects [37-40] on the settlement of invertebrates and algae. The mode of action of facilitative effects can reach from passive entrapment to active attraction and both mechanisms may act simultaneously. In our experiment, settlement of Obelia sp., which can also proliferate by the regeneration of hydroid fragments, could have been enhanced by the entrapment of drifting fragments and/or larvae in sticky extracellular polymers. Additionally or alternatively, larvae could have been attracted by chemical cues released from the biofilm [41]. We consider this model to be the most likely explanation for the observations we made and if it is correct, the facilitation effect exerted by Diplosoma was limited to the moment of settlement and cannot have promoted hydrozoan post-settlement growth.

Further alternative models that could explain not only increased settlement but also increased growth in Obelia sp. on tiles carrying Diplosoma are (1) the alteration of habitat structure by the tunicates with consequences for small-scale hydrodynamics that facilitate larval settlement and/or lead to a reduction in the speed of water currents (the latter may enhance food capture rates in the hydrozoan); or (2) the pumping activity of the colonial ascidians, which, similar to the three-dimensional structure, might modify water movements in the benthic boundary layer with positive effects on other filter or tentacle feeders, e.g. by increasing the availability of food [42]. Facilitative effects of residents on the recruitment of other species can also be the consequence of increased habitat complexity [43-45]. However, we assume that this does not play a role in the case of Diplosoma, because the colonial ascidian has an encrusting growth form and does not build complex structures.

At the study site that was more protected (site B), the effect of Diplosoma cover was more pronounced since both density levels provoked an initial effect and it lasted longer than at site A. Possibly this was because of a higher abundance of larvae or of drifting colony fragments in the more turbulent waters, what lead to a faster colonization that quickly overrode the initial effect of Diplosoma. The fact that we replicated this study only at one exposed and at one protected site does not allow a general conclusion about the possible influence of hydrodynamic forces on the initial effect of Diplosoma, since we cannot exclude that other site-specific characteristics were responsible for the picture we observed. However, when we inspected both study sites before the start of the experiment no other potentially relevant site characteristics were detected [see also 24].

In this experiment, all tiles were completely occupied by macrofoulers after 2 months; total cover averaged across all tiles at the last sampling event was $99 \%$. A set of 6 organisms constituted $\sim 70 \%$ of the assemblages on the effectively available tile surface area: the bryozoan Bugula neritina (mean cover across all tiles: $12 \% \pm 7 \% \mathrm{SD}$ ), green algae of the order Ulvales ( $7 \% \pm 8 \%$ ), the brown alga Ectocarpus sp. $(23 \% \pm 22 \%)$, the red alga Polysiphonia sp. (9\% $\pm 7 \%)$, the hydrozoan Tubularia sp. (3\% $\pm 5 \%)$, and Diplosoma sp. $(16 \% \pm 20 \%)$. For Ectocarpus sp. and for the green algae we found that at the last sampling day their cover correlated negatively with the abundance of Obelia sp. The latter is known as a successful primary colonizer, which can rapidly occupy bare substrata and dominate communities at early successional stages or in disturbed environments [46-48]. However, it can presumably not persist in the presence of competitors [23, 49]. We therefore assume that in our experiment, Obelia sp. was partly outcompeted and replaced by other colonizers such as Ectocarpus sp. or green algae. Although both of them are also opportunistic species that constitute rather weak competitors, they may have overgrown Obelia sp. and cut it off from food supply. This process was apparently independent of Diplosoma presence and therefore obliterated the initial differences between tiles carrying Diplosoma colonies and those that were empty.

Our results are important for understanding community succession in marine benthic habitats. It has been hypothesized that initial colonizers can preempt space and other resources and by this drive community succession into a particular direction [47]. This would mean that, depending on which species settles first, communities, which establish on similar substrata in the same region, can develop into different directions and may then sharply differ in composition and structure. This, in turn, could also lead to differences in energy and matter fluxes through these communities. However, our findings confirm previous studies from the same study system which showed that-although initial differences between them occurred-hardbottom communities converge at later successional stages. This is mainly due to competitively dominant species, which suppress others and can by this dominate fouling communities [27, 50]. So, at least in the highly productive Chilean system which we investigated, differences in substratum properties [27] or in the arrival sequence of initial colonizers [24, 50, this study] can be relevant at early successional stages, but disappear once dominant competitors colonize and expand in the communities. 


\section{Conclusions}

In summary, we can conclude that the presence of $D$. listerianum increased the settlement and/or the postsettlement growth in the opportunistic colonizer Obelia sp. at a very early successional stage, but did not enhance the recruitment, i.e. the long-term post-settlement survival, of the hydrozoan. The strength of the effect differed between locations although it is not clear what mechanism was responsible for this. Over larger timescales, however, community structure remained unaffected by the initial presence of the ascidian, most likely because the species initially favoured by Diplosoma as well as the ascidian itself were replaced by stronger competitors during the course of succession [51]. Therefore, in our system, Diplosoma was not a founder species that determined the later course of community succession. It is more likely that species identity and competitiveness drove the long-term composition of the benthic communities in La Herradura Bay [50]. The invasive potential of Diplosoma species, which is well documented by numerous invasions that have been reported from all over the world [52-54], suggests that this genus will become abundant in benthic habitats from which it is currently still absent in the future. We therefore think that further studies on the short- and long-term effects of this ascidian on fouling processes are needed.

\section{Abbreviations}

ANOVA: analysis of variance; PVC: polyvinyl chloride.

\section{Authors' contributions}

IK ran the experiments, collected the data, did the initial statistical analyses and prepared the initial draft of the manuscript. ML conducted the final data analyses as well as helped with the interpretation of the results and wrote the final manuscript. MT designed the study, supervised the practical work and participated in the writing of the manuscript. All authors read and approved the final version of the manuscript.

\section{Author details \\ ${ }^{1}$ Institute for Evolution and Biodiversity, Westfälische Wilhelms-Universität Münster, Hüfferstraße 1, 48149 Münster, Germany. ${ }^{2}$ Marine Ecology Depart- ment, GEOMAR Helmholtz Centre of Ocean Research Kiel, Duesternbrooker Weg 20, 24105 Kiel, Germany. ${ }^{3}$ Facultad Ciencias del Mar, Universidad Católica del Norte, Larrondo 1281, Coquimbo, Chile. ${ }^{4}$ Millennium Nucleus Ecology and Sustainable Management of Oceanic Island (ESMOI), Coquimbo, Chile. \\ ${ }^{5}$ Centro de Estudios Avanzados en Zonas Áridas (CEAZA), Coquimbo, Chile. \\ ${ }^{6}$ Present Address: Ecologic Institut, Pfalzburger Str 43/44, 10717 Berlin, Germany.}

\section{Acknowledgements}

This study was conducted as part of the international research programme GAME (Global Approach by Modular Experiments) and was funded by the Mercator Stiftung (Essen, Germany). Mauricio Cifuentes helped with the construction of the experimental set-up. We thank Leonardo Enrique Miranda Guerra and Juan-Carlos Astudillo for help in the field. Field support was also given by the boat crew of the Universidad Católica del Norte. Two anonymous reviewers contributed substantially to the overall quality of the manuscript.

\section{Competing interests}

The authors declare that they have no competing interests.

\section{Availability of data and materials}

The data sets supporting the conclusions of this article are available in the PANGAEA repository, https://doi.org/10.1594/PANGAEA.887385.

\section{Consent for publication}

Only applicable after acceptance.

\section{Ethics approval and consent to participate}

All applicable international, national, and/or institutional guidelines for the care and use of animals were followed. This article does not contain any studies with human participants performed by any of the authors.

\section{Funding}

This study was funded by Stiftung Mercator (Essen, Germany).

\section{Publisher's Note}

Springer Nature remains neutral with regard to jurisdictional claims in published maps and institutional affiliations.

Received: 9 August 2017 Accepted: 7 March 2018

Published online: 27 March 2018

References

1. Connell JH. The consequences of variation in initial settlement versus post-settlement mortality in rocky intertidal communities. J Exp Mar Biol Ecol. 1985:93:11-45.

2. Pineda S, Starczak V, Stueckle TA. Timing of successful settlement: demonstration of a recruitment windowin the barnacle Semibalanus balanoides. Mar Ecol Prog Ser. 2006;320:233-7.

3. Sutherland JP, Karlson RH. Development and stability of the fouling community at Beaufort, North Carolina. Ecol Monogr. 1977:47:425-46.

4. Sams MA, Keough MJ. Early recruitment variation and an established dominant alter the composition of a temperate fouling community. Mar Ecol Prog Ser. 2013;486:79-91.

5. Bingham BL. Life histories in an epifaunal community: coupling of adult and larval processes. Ecology. 1992;73:2244-59.

6. Grosberg RK. Competitive ability influences habitat choice in marine invertebrates. Nature. 1981;290:700-2.

7. André $C$, Jonsson PR, Lindegarth M. Predation on settling bivalve larvae by benthic suspension feeders: the role of hydrodynamics and larval behaviour. Mar Ecol Prog Ser. 1993;97:183-92.

8. Hunt HL, Scheibling RE. Role of early post-settlement mortality in recruitment of benthic marine invertebrates. Mar Ecol Prog Ser. 1997:155:269-301.

9. Lambert G, Lambert CC. Lambert CC Non-indigenous ascidians in southern California harbors and marinas. Mar Biol. 1998;130:675-88.

10. Bullard SG, Lambert G, Carman MR, Byrnes J, Whitlatch RB, Ruiz G, Miller RJ, Harris L, Valentine PC, Collie JS, Pederson J, McNaught DC, Cohen AN, Asch RG, Dijkstra J, Heinonen K. The colonial ascidian Didemnum sp. A: current distribution, basic biology and potential threat to marine communities of the north-east and west coasts of North America. J Exp Mar Biol Ecol. 2007;342:99-108.

11. Osman RW, Whitlatch RB. The influence of resident adults on recruitment: a comparison to settlement. J Exp Mar Biol Ecol. 1995;190:169-98.

12. Stachowicz JJ, Whitlatch RB, Osman RW. Species diversity and invasion resistance in a marine ecosystem. Science. 1999;286:1577-9.

13. Lindeyer F, Gittenberger A. Ascidians in the succession of marine fouling communities. Aquat Inv. 2011;6:421-34.

14. Paetzold SG, Giberson GJ, Hill J, Davidson JDP, Davidson J. Effect of colonial tunicate presence on Ciona intestinalis recruitment within a mussel farming environment. Manag Biol Inv. 2012;3:15-23.

15. Lambert G. Ecology and natural history of the protochordates. Can J Zool. 2005;83:34-50

16. Osman RW, Whitlatch RB. The influence of resident adults on larval settlement: experiments with four species of ascidians. J Exp Mar Biol Ecol. 1995:190:199-220.

17. Stoecker D. Resistance of a tunicate to fouling. Biol Bull. 1978;155:615-26. 
18. Stoecker D. Chemical defenses of ascidians against predators. Ecology. 1980;61:1327-34

19. Davis AR, Campbell DJ. Two levels of spacing and limits to local population density for settled larvae of the ascidian Clavelina moluccensis: a nearest-neighbour analysis. Oecologia. 1996;108:701-7.

20. Pisut DP, Pawlik JR. Anti-predatory chemical defenses of ascidians: secondary metabolites or inorganic acids? J Exp Mar Biol Ecol. 2002;270:203-14.

21. Bullard SG, Whitlatch RB, Osman RW. Checking the landing zone: do invertebrate larvae avoid settling near superior spatial competitors? Mar Ecol Prog Ser. 2004:280:239-74.

22. Bullard SG, Shumway SE, Davis CV. The use of aeration as a simple and environmentally sound means to prevent biofouling. Biofouling. 2010;26:587-93.

23. Mizrahi D, Pereira SF, Navarette SA, Flores AAV. Allelopathic effects on the sun-coral invasion: facilitation, inhibition and patterns of local diversity. Mar Biol. 2017;164:139.

24. Cifuentes M, Krüger I, Dumont CP, Lenz M, Thiel M. Does primary colonization or community structure determine the succession of fouling communities? J Exp Mar Biol Ecol. 2010;395:10-20.

25. Dumont CP, Gaymer CF, Thiel M. Predation contributes to invasion resistance of benthic communities against the non-indigenous tunicate Ciona intestinalis. Biol Invasions. 2011;13:2023-34.

26. Dumont CP, Harris LG. Gaymer CF Anthropogenic structures as a spatial refuge from predation for the invasive bryozoan Bugula neritina. Mar Ecol Prog Ser. 2011:427:95-103.

27. Bravo M, Astudillo JC, Lancellotti D, Luna-Jorquera G, Valdivia N, Thiel M. Rafting on abiotic substrata: properties of floating items and their abundance on community succession. Mar Ecol Prog Ser. 2011:439:1-17.

28. Meese RJ, Tomich PA. Dots on the rocks: a comparison of percent cover estimation methods. J Exp Mar Biol Ecol. 1992;165:59-73.

29. Young CM. Ascidian cannibalism correlates with larval behavior and adult distribution. J Exp Mar Biol Ecol. 1988;117:9-26.

30. Wahl M. Small scale variability of benthic assemblages: biogenic neighbourhood effects. J Exp Mar Biol Ecol. 2001;258:101-14.

31. Crisp DJ, Ryland JS. Influence of filming and of surface texture on settlement of marine organisms. Nature. 1960;185:119.

32. Kirchman D, Mitchell R. A biochemical mechanism for marine biofouling. Oceans. 1981;13:537-41.

33. Cooksey KE, Wigglesworth-Cooksey B. Adhesion of bacteria and diatoms to surfaces in the sea: a review. Aquat Microb Ecol. 1995;9:87-96.

34. Mihm JW, Banta WC, Loeb Gl. Effects of adsorbed organic and primary fouling films on bryozoan settlement. J Exp Mar Biol Ecol. 1981;54:167-79.

35. Maki JS, Little BJ, Wagner P, Mitchell R. Biofilm formation on metal surfaces in antarctic waters. Biofouling. 1990;2:27-38.

36. Zapata M, Silva F, Luza Y, Wilkens M, Riquelme C. The inhibitory effect of biofilms produced by wild bacterial isolates to the larval settlement of the fouling ascidia Ciona intestinalis and Pyura praeputialis. Electron J Biotechnol. 2007;10:149-59.

37. Crisp DJ. Factors influencing the settlement of marine invertebrate larvae. In: Grant PT, Mackie AM, editors. Chemoreception in marine organisms. New York: Academic Press; 1974. p. 177-265.
38. Pawlik JR. Chemical ecology of the settlement of benthic marine invertebrates. In: Barnes M, Ansell AD, Gibson RN, editors. Oceanography and marine biology, vol. 30., An annual reviewLondon: UCL Press; 1992. p. 273-335.

39. Negri AP, Webster NS, Hill RT, Heyward AJ. Metamorphosis of broadcast spawning corals in response to bacteria isolated from crustose algae. Mar Ecol Prog Ser. 2001;223:121-31.

40. Lam C, Harder T, Qian P-Y. Induction of larval settlement in the polychaete Hydroides elegans by extracellular polymers of benthic diatoms. Mar Ecol Prog Ser. 2005;286:145-54.

41. Wieczorek SK, Todd CD. Inhibition and facilitation of bryozoan and ascidian settlement by natural multi-species biofilms: effect of film age and the roles of active and passive larval attachment. Mar Biol. 1997;128:463-73.

42. Sousa WP. The role of disturbance in natural communities. Annu Rev Ecol Syst. 1984;15:353-91.

43. Bostroem C, Bonsdorff E. Zoobenthic community establishment and habitat complexity - the importance of seagrass shoot-density, morphology and physical disturbance for faunal recruitment. Mar Ecol Prog Ser. 2000;205:123-38.

44. Bradshaw C, Collins P, Brand AR. To what extent does upright sessile epifauna affect benthic biodiversity and community composition? Mar Biol. 2003;143:783-91.

45. Moertl M, Rothhaupt K-O. Effects of adult Dreissena polymorpha on settling juveniles and associated macroinvertebrates. Int Rev Hydrobiol. 2003:88:561-9.

46. Murray SN, Littler MM. Patterns of algal succession in a perturbated marine intertidal community. J Phycol. 1978;14:506-12.

47. Sousa WP. Experimental investigations of disturbance and ecological succession in a rocky intertidal algal community. Ecol Monogr. 1979:49:227-54.

48. Breves-Ramos A, Passeri Lavrado H, Ribeiro Junqueira ADO, Gonçalves da Silva SH. Succession in rocky intertidal benthic communities in areas with different pollution levels at Guanabara Bay (RJ-Brazil). Braz Arch Biol Technol. 2005:48:951-65.

49. Forde SE, Raimondi PT. An experimental test of the effects of variation in recruitment intensity on intertidal community composition. J Exp Mar Biol Ecol. 2004;301:1-14.

50. Cifuentes M, Kamlah K, Thiel M, Lenz M. Wahl M Effects of temporal variability of disturbance on the succession in marine fouling communities in northern-central Chile. J Exp Mar Biol Ecol. 2007;352:280-94.

51. Valdivia N, Heidemann A, Thiel M, Molis M, Wahl M. Effects of disturbance on the diversity of hard-bottom macrobenthic communities on the coast of Chile. Mar Ecol Prog Ser. 2005;299:45-54.

52. Agius BP. Spatial and temporal effects of pre-seeding plates with invasive ascidians: growth, recruitment and community composition. J Exp Mar Biol Ecol. 2007;342:30-9.

53. Dijkstra J, Harris LG, Westerman E. Distribution and long-term temporal patterns of four invasive colonial ascidians in the Gulf of Maine. J Exp Mar Biol Ecol. 2007;342:61-8.

54. Gittenberger A. Recent population expansions of non-native ascidians in the Netherlands. J Exp Mar Biol Ecol. 2007;342:122-6.

\section{Submit your next manuscript to BioMed Central and we will help you at every step:}

- We accept pre-submission inquiries

- Our selector tool helps you to find the most relevant journal

- We provide round the clock customer support

- Convenient online submission

- Thorough peer review

- Inclusion in PubMed and all major indexing services

- Maximum visibility for your research

Submit your manuscript at www.biomedcentral.com/submit 